\title{
CAMINHOS DIFERENTES DA AMERICANIZAÇÃO NA EDUCAÇÃO EM ADMINISTRAÇÃO NO BRASIL: A EAESP/FGV E A FEA/USP
}

\author{
THE DIFFERENT PATHS OF AMERICANIZATION \\ IN MANAGEMENT EDUCATION, IN BRAZIL: \\ EAESP/FGV AND FEA/USP
}

Recebido em: 26/03/2013 - Aprovado em: 24/05/2013

Avaliado pelo sistema double blind review Editora Científica: Manolita Correia Lima

\section{MIRIAM PIRES EUSTACHIO DE MEDEIROS VALE vale.miriam@gmail.com CARLOS OSMAR BERTERO \\ RAFAEL ALCADIPANI DA SILVEIRA}

ESCOLA DE ADMINISTRAÇÃO DE EMPRESAS DE SÃO PAULO - FUNDAÇÃO GETÚLIO VARGAS

\section{RESUMO}

O artigo apresenta as conclusões da pesquisa sobre a fundação e o desenvolvimento de duas importantes escolas de administração no Brasil, a Faculdade de Economia, Administração e Contabilidade da Universidade de São Paulo (FEA/USP) e a Escola de Administração de Empresas de São Paulo da Fundação Getúlio Vargas (EAESP/FGV). Ambas as instituições foram profundamente influenciadas pelas ideias do Management vindas dos Estados Unidos que se disseminaram depois do fim da Segunda Guerra Mundial. A maneira que a influência americana chegou às duas instituições foi diferente. A EAESP/FGV contou com uma missão composta por professores americanos que administraram academicamente a escola por pelo menos dez anos. O mesmo grupo de professores também teve sua influência sobre a usp, primeiramente na Escola Politécnica e depois no departamento de administração da FEA. Entretanto, o produto final quando comparamos uma instituição de ensino com a outra foi diferente. Cada escola desenvolveu sua própria identidade e sua maneira de ensinar e pesquisar sobre administração. A pesquisa, nesse artigo, seguiu uma metodologia historiográfica e pode ser considerada uma contribuição à crescente literatura sobre a propagação mundial do Management americano. Além disso, apresentamos o contexto brasileiro das décadas de 50 e 60 que foram primordiais para que a influência americana se fizesse sentir e espalhar, inclusive no cenário educacional brasileiro.

Palavras-chave: Educação em Administração; Escolas Brasileiras de Administração; Influência do Management Americano; Contexto Brasileiro das décadas de 50 e 60; Historiografia da Educação em Administração.

\footnotetext{
ABSTRACT

This paper presents the conclusions of research on the founding and development of two important Management schools in Brazil: São Paulo University's College of Economics, Management and Accounting, and the Getúlio Vargas Foundation's São Paulo School of Management. Both institutions were deeply influenced by the spread of US Management ideas following the end of World War II, but the manner in which the American influence arrived to each school was different. The São Paulo School of Management had a mission of American professors academically running the school for over a decade. This same group of professors also made their influence felt at the University of São Paulo, first at the College of Engineering and then at the management department of the College of Economics, Management and Accounting. However, the final products were different, since each school developed its own identity and way in which they approached management teaching and research. Nowadays, both maintain outstanding positions among Brazil's institutions. The methodology used was historiographical and can be considered a contribution to the growing literature on the spread of US Management education worldwide. It also summarizes the Brazilian context in the 1950 s and 1960 s as it relates to the first steps by the influence of US Management education in the country.

Keywords: Management Education; Brazilian Management Schools; US Management Influence; Brazilian Context in the 1950 and 1960s; Management Education Historiography.
} 


\section{INTRODUÇÃO}

Este artigo analisa o surgimento de duas das principais escolas brasileiras de administração de empresas no Brasil, a Escola de Administração de Empresas de São Paulo da Fundação Getúlio Vargas (EAESP/FGv) e a Faculdade de Economia, Administração e Contabilidade da Universidade de São Paulo (FEA/USP), a fim de investigar a influência dos Estados Unidos no estabelecimento e desenvolvimento de ambas as instituições, inserindose no crescente interesse por conhecer o desenvolvimento da educação em administração e da teoria administrativa fora do eixo Estados Unidos/Europa Ocidental (ÜSDIKEN; WASTI, 2009; KIPPING; ENGWALL; ÜSDIKEN, 2009; SRINIVAS, 2009; AlCADipani; CALDAS, 20I2; BARRos, 20I3). Cursos de administração se tornaram muito atraentes no Brasil na segunda metade do século $\mathrm{xx}$, a ponto de atualmente $16 \%$ das vagas em cursos de graduação estarem alocadas à administração, distribuídas em mais de 2.000 cursos. Isto envolve aproximadamente um milhão de estudantes e um corpo docente de 200.000 professores. Estes números disponibilizados pelo Ministério da Educação (INEP, 20II) são suficientes para justificar o interesse e a importância que tem o entendimento das raízes históricas da educação em administração no nosso país.

Assiste-se a um interesse crescente pela análise da Americanização do ensino e da pesquisa em administração (ÜsDIKEN, 2004, FRENKEL; SHENHAV, 2003). Americanização define-se como um processo pelo qual os modelos norte-americanos foram aplicados em diversas partes do mundo. Embora seja possível localizar sinais de Americanização antes da Segunda Guerra Mundial, o processo aumentou decididamente depois da guerra (CLARK; ROWLINSON, 2004). As iniciativas norte-americanas foram apoiadas por instituições estadunidenses que buscavam a disseminação da administração e das técnicas de produção daquele país (ÜSDIKEN; ÇETIN, 200I).

Todavia, há variações entre as nações na aceitação do estilo de administrar e na educação provenientes dos Estados Unidos. A literatura indica que houve uma convergência das nações europeias na adoção do modelo americano de gestão, bem como na educação de administradores 
(ÜSDIKEN, 2004). Com base numa perspectiva neocolonial, observou-se que a influência norte-americana no desenvolvimento da gestão e da educação de administradores foi muito além da Europa num processo que se assemelha à colonização (FRENKEL; SHENHAV, 2003).

Desta maneira, neste artigo serão comparados dois modos de Americanização, objetivando mostrar como esse processo difere num mesmo país, preenchendo uma lacuna na literatura ao indicar que a Americanização não é um processo único.

\section{A ASCENSÃO DA EDUCAÇÃO NORTE-AMERICANA DE ADMINISTRADORES}

A importância do aparecimento da educação norte-americana de administradores (Management) é bem conhecida e coberta por vasta literatura. Nossa intenção é tratar o assunto com base na perspectiva brasileira durante os anos de 1950 e 1960, quando as duas instituições aqui estudadas iniciaram suas atividades, tornando-se centros importantes para o desenvolvimento e difusão da educação de administradores no Brasil.

O Brasil pertence a um grupo de países que consideravam durante boa parte do século $\mathrm{xx}$ a industrialização como o caminho seguro e natural para o desenvolvimento econômico. Quando a Segunda Guerra Mundial terminou, a economia ainda dependia do setor primário, tendo na exportação do café sua principal fonte de divisas (BAER, 2009; FAUsTO, 1995). Embora a industrialização brasileira tenha começado no início do século passado, o passo acelerou depois do término da Segunda Guerra. Neste processo, a liderança coube a empreendedores brasileiros e ao Estado, que foi responsável não só pela formulação e implantação da política econômica, mas em vários ramos atuou também ativamente, gerando um grande número de empresas estatais que ainda hoje estão em atividade. Mas a industrialização brasileira não teria se completado se não houvesse uma entrada maciça de investimentos estrangeiros criando no país um grande número de subsidiárias de empresas multinacionais, com as norteamericanas ocupando, durante muito tempo, o primeiro lugar entre as responsáveis pelos Investimentos Diretos Estrangeiros (IDES). 
Até a metade do século XX, a influência cultural predominante no Brasil foi a França, seguida da Inglaterra e da Alemanha. A influência dos Estados Unidos surgiu apenas depois do final da Segunda Guerra, quando aquele país firma sua caminhada em direção à condição de superpotência, posição que hoje ainda detém. As duas instituições aqui consideradas, a EAESP/FGV e a FEA/USP foram as duas escolas mais marcadas e diretamente influenciadas pelo modelo norte-americano de administração (Management) no período em que este enfrentava um momento decisivo de mudança devido às críticas que sofria no país de origem. Houve uma influência também na Escola Superior de Administração e Negócios (ESAN) que pertencia à antiga Faculdade de Engenharia Industrial, hoje Fundação Educacional Inaciana (FEI), em São Paulo, por meio do Padre Sabóia de Medeiros, figura importante da FEI e que tinha um parente que era embaixador do Brasil nos anos de 1950 nos eUA. Porém, a ESAn não conseguiu o destaque das instituições analisadas aqui, mesmo tendo usado como modelo a Graduate School of Business Administration da Universidade de Harvard, algo que ainda carece de análise mais profunda (BERTERO, 2006; TAYLOR, I968). A influência americana mais direta se fez sentir sobre a EAESP/FGV que foi iniciada por uma missão universitária da Michigan State University (MSU). Desde o primeiro instante, o modelo norte-americano de administração (Management) foi considerado o mais "moderno" e adequado para gerir as organizações e particularmente as empresas. Alguns traços da influência europeia, provenientes do passado, de origem italiana e francesa, seriam possíveis competidores, mas foram rapidamente descartados em favor do modelo norte-americano (ALCADIPANI; BERTERO, 20I2).

Porém, no final dos anos de 50 e 60 do século passado, quando o modelo de administração norte-americano ensaiava os primeiros passos para firmar-se no Brasil, a educação em administração passava por severas críticas no próprio Estados Unidos. O texto clássico que contém essas críticas passou a ser conhecido como o Ford Foundation Report (Relatório da Fundação Ford) sobre o estado da educação em administração de empresas naquele país (GORDON; HOwELL, 1959). O relatório criticava a falta de fundamentação científica do que era ensinado em cursos de administração 
de negócios, que se limitavam a casos e a um conteúdo de best practices. Demandava-se que os cursos fossem teoricamente mais robustos e isso se conseguiria com programas sistemáticos de pesquisa em administração. Igualmente, criticava-se a formação dos corpos docentes, ainda, na época, com predominância de profissionais sem titulação acadêmica, mestrado ou doutorado. O interessante, como será visto a seguir, é que o conteúdo programático do curso de graduação desenvolvido para a EAESP/FGV incorporava parte das críticas contidas no Relatório da Fundação Ford. Os quatro semestres iniciais de um total de oito semestres incluíam disciplinas de ciências sociais, mais matemática, estatística e contabilidade, lançando os fundamentos para os cursos de áreas funcionais de administração de negócios que deveriam ser cientificamente fundamentadas. Ainda na fase inicial do projeto da nova escola, os professores norte-americanos tiveram o cuidado de criar um Centro de Pesquisas e Publicações, adequandose às recomendações do Relatório da Fundação Ford de que a educação em administração de empresas deveria abandonar programas centrados exclusivamente em best practices, adotando uma abordagem mais científica da administração, incluindo a fundamentação nas várias ciências sociais (economia, direito, ciência política, psicologia, sociologia, antropologia, etc.) e direcionando recursos financeiros e humanos (professores) para a realização de pesquisas que gerariam conhecimento administrativo cientificamente fundamentado e aplicado (TAYLOR, I968).

De uma perspectiva brasileira é importante entender o porquê e o como o modelo norte-americano (Management) veio a ser escolhido para adoção numa área de educação que então se iniciava. O modelo norteamericano espalhou-se pelo mundo rapidamente e no Brasil isso aconteceu simultaneamente com o processo de industrialização.

Em meados do século $\mathrm{xx}$, a maioria dos brasileiros tinha uma imagem bastante favorável dos Estados Unidos. É fato que certo antiamericanismo sempre esteve presente na cultura brasileira, especialmente entre a esquerda, mas a imagem era positiva junto à elite empresarial e para a crescente burguesia urbana. Isto pode ser devido a diversas causas, sendo uma delas os efeitos da Política de Boa Vizinhança (Good Neighborhood 
Policy) do presidente Franklin Delano Roosevelt durante a década de 1930 e início dos anos de 1940, quando se tentou o estabelecimento de relações mais cordiais e amistosas com a América Latina, após um longo período de "porrete e cenoura" (stick and carrot) praticada durante as três décadas iniciais do século passado. A aproximação com os Estados Unidos produziu efeitos imediatos. O Brasil uniu-se ao esforço de guerra aliado enviando tropas para combater na Itália, sob o comando norte-americano, e cedeu parte do território nacional para o estabelecimento de bases da Força Aérea dos Estados Unidos.

Então, os Estados Unidos surgiam para muitos brasileiros como o vencedor da Guerra contra o nazi-fascismo e o líder indisputado do Ocidente. Antigos aliados se tornavam competidores pela liderança mundial, como aconteceu com a antiga União Soviética. A China deixou de ser um aliado com a vitória da Revolução Comunista e a Guerra Fria estava em gestação. À medida que as relações internacionais se tornavam mais tensas e a Guerra Fria se desdobrava no início da década de 1950 (HIRST, 2009), o Brasil não hesitou em seguir o Ocidente sob a liderança dos Estados Unidos. Tratava-se de um alinhamento quase automático, com breves interrupções. Houve um possível "alinhamento" pelo governo brasileiro com os chamados "países não alinhados", mas logo foi abandonado. As relações Brasil/Estados Unidos passaram por várias mudanças, contudo nunca foram muito previsíveis. Em vários momentos, ambas as nações se mostraram reciprocamente desapontadas, mas no período aqui considerado, as relações eram muito favoráveis o que tornou a cooperação possível e eficaz.

Todavia, o que foi decisivo para que o modelo de administração norteamericano fosse aceito no Brasil foi a identificação de tudo que fosse americano com modernidade, algo considerado positivo e que deveria ser adotado. As críticas que surgiram com a pós-modernidade e com a pósindustrialização ainda estavam num futuro a três décadas de distância. A modernidade tinha os seus correlatos como o desenvolvimento econômico, industrialização e uma mudança de valores que apelavam para um modo de vida mais secular, e principalmente propunham instituições políticas democráticas. O Brasil estava saindo de um longo período de ditadura civil 
sob o comando de Getúlio Vargas e o país promulgara recentemente uma nova Constituição que estabelecia uma democracia representativa com separação de poderes e que assegurava um sistema econômico capitalista ou de economia de mercado.

Mas a grande legitimação do modelo americano de gestão (Management) foi assegurada, acima de tudo, pelo fulgurante sucesso econômico dos Estados Unidos. O último século foi com frequência e acertadamente chamado de um século americano. Isto era particularmente claro na economia e na tecnologia. A economia dos Estados Unidos respondia por mais da metade do produto industrial do mundo. A indústria automotiva era basicamente uma indústria americana. A Europa jazia em ruínas e o Japão, que nos anos de I980 tornar-se-ia uma das grandes economias do mundo, ancorada fundamentalmente no setor manufatureiro, ainda estava em processo de reconstrução. Os Estados Unidos erguia-se solitário, como líder econômico e em grande medida como responsável pela recuperação econômica da Europa Ocidental.

O Brasil também passava por grandes mudanças. Durante a maior parte da história da nação, a cidade do Rio de Janeiro foi o centro político, econômico e cultural da colônia e posteriormente da nação independente. Mas à medida que o século $\mathrm{xx}$ avançou, São Paulo foi se tornando uma cidade mais influente e poderosa. O ponto de inflexão da modesta província ocorreu quando o café passou a ser o produto de maior importância da economia brasileira, tornando o país mundialmente conhecido como o maior produtor de tais grãos. O café certamente lançou os fundamentos para que se acumulasse capital, o que tornou a industrialização possível. No final do século xix e inícios do século xx, São Paulo atraía imigrantes para um país que nunca tinha sido um destino importante de emigrantes. Vieram predominantemente da Europa Ocidental, mas também do Japão. Trouxeram consigo um impulso empreendedor e muitos se tornaram empresários industriais bem sucedidos, unindo-se aos comerciantes e fazendeiros de café na edificação do centro econômico paulista que lideraria economicamente o Brasil durante o restante do século (MARCOVITCH, 2007). 
São Paulo, como a capital do estado homônimo foi o local escolhido pela Fundação Getúlio Vargas e aceito pela missão da MSU como o sítio adequado para erigir uma escola de administração de empresas. Era um importante centro econômico e ainda em processo de crescimento. Portanto, o que explica o triunfo precoce do modelo de administração (Management) norteamericano foi um conjunto de razões que eram interesses convergentes (TAYLOR, I968).

A ascensão do Management pode também ser entendida como parte da consolidação dos Estados Unidos como superpotência mundial (ALCADIPANI; BERTERO, 20I2). É inegável que o modelo de gestão americano é percebido como eficiente e eficaz não só como instrumento de gestão, mas também como aparato teórico de administração. Mas a superação do que existia de experiência e conhecimentos administrativos na tradição europeia em países como a Alemanha, França, Itália e Inglaterra deveu-se ao fato de que por trás do modelo americano estava o superpoder nacional dos Estados Unidos (ALCADIPANI; BERTERO, 20I2). No caso da experiência brasileira havia duas escolas importantes, a EAESP/FGV e a FEA/USP, ambas localizadas em São Paulo que era então o centro econômico brasileiro em ascensão num momento em que a industrialização era vista como um sinal definitivo de modernização. A associação com os Estados Unidos foi em grande medida desejada pela burguesia urbana e vista como um ativo no caminho para a modernização e desenvolvimento (CARDoso; Faletto, 2004). O que fez com que ambas as instituições buscassem e voluntariamente aceitassem a proposta do modelo de gestão norte-americano foi a convergência de interesses dos parceiros: o Governo Brasileiro, representado pela Fundação Getúlio Vargas, alguns professores que integravam o corpo docente da Universidade de São Paulo, a nascente burguesia industrial e, naturalmente, os Estados Unidos que assistia aos desdobramentos da Guerra Fria. 


\section{METODOLOGIA}

Este artigo se baseia em dados diversos conseguidos sobre as duas escolas de administração estudadas e mais especificamente sobre o início dos cursos de administração de empresas nas duas instituições de ensino superior. Conseguimos alguns livros que falavam um pouco sobre a história das duas relevantes instituições de ensino. No caso da FEA/USP, nos deparamos com um livro escrito pelos professores daquela faculdade na comemoração de seus 35 anos de existência, em I98I. O livro foi publicado um pouco depois, no ano do cinquentenário da usp, em i984. Intitulado História da Faculdade de Economia e Administração da Universidade de São Paulo, foi escrito por vinte e cinco autores em dois volumes. Outro livro primordial em nossas pesquisas e que nos colocou "em contato" com o já falecido professor Ruy Aguiar da Silva Leme foi a Reestruturação Didática da Faculdade de Ciências Econômicas e Administrativas da USP O livro, de 1960, foi escrito quando da volta da viagem de uma comissão formada por professores da FEA/USP para os Estados Unidos. Essa comissão visava reestruturar os cursos da Faculdade uma vez que a cada ano, vinham recebendo menos alunos. Ao final do livro do professor Ruy Leme, há o decreto $n^{\circ}$ 36.36I de 8 de março de 1960 que efetivamente modificou os cursos da FEA/USP e pavimentou uma via que levaria à criação do curso de administração de empresas em 1964 nessa instituição. Em seguida, buscamos literatura que tratava da história da EAESP/FGV (TAYLOR, I968; D’ARAUJO, I999; COIMBRA, 2007; ALCADIPANI; BERTERO, 2OI2).

Consultamos também as minutas do Conselho de Administração da EAESP/ FGV entre I954 a 1965 quando a profissão de administrador foi regulamentada pela Lei $n^{\circ}$ 4.769, de 9 de setembro de 1965. Analisamos igualmente as Atas da Congregação da FEA/usp que compreendem o período desde sua criação em agosto de 1946 até o fim do ano de I965, um ano depois da instituição do curso de administração de empresas nessa faculdade. (ATKINSON; COFFEY, I998).

Além disso, foram entrevistados professores titulares e ex-diretores da FEA/USP. A primeira entrevista foi feita no dia Io de março de 20 I e a última 
no dia 29 de novembro do mesmo ano, sendo que todas foram gravadas resultando em um total de mais de dezesseis horas de relatos sobre o assunto. Tão logo terminávamos de fazer as entrevistas, transcrevíamos todo o material para logo em seguida, analisa-lo. Assim, pessoas que participaram do estabelecimento das duas escolas puderam efetivamente contribuir com seus depoimentos orais para a reconstrução do momento aqui estudado. (FONTANA; FREY, 2000).

Adicionalmente, alguns materiais, como palestras e apresentações, presentes no website da FEA/Usp foram acessados, seguindo a crescente tendência de utilização de fontes orais que possam enriquecer a pesquisa (GARRIDO, I993; CURADO, 200I; BOOTH; ROWLINSON, 2006). Há inclusive um canal exclusivo de vídeos no site da instituição que facilitou a pesquisa (FACULDADE DE ECONOMIA, ADMINISTRAÇÃO E CONTABILIDADE DA UNIVERSIDADE DE SÃO PAULO, 2008). As pessoas entrevistadas e aquelas cujas falas foram analisadas pelo canal de vídeo no website eram todos professores antigos das instituições, alguns já aposentados, e que estiveram mais próximos ou envolvidos nos eventos aqui analisados, por terem participado no estabelecimento das escolas.

Durante as entrevistas com os professores da FEA/USP recebemos mais material para a pesquisa. Exemplos de material que nos foi fornecido foram: o livro A FEA-USP no tempo: contribuição à memória de seus 60 anos (PINHO, 2006), nos foi emprestado, uma coleção de jornais editados pelos próprios alunos, com destaque para o jornal O Canguru (I957) onde um discurso do professor Antonio Delfim Netto proferido durante a formatura da turma de 1956 foi transcrito.

Com todo o material reunido, passamos a escrever primeiramente sobre a história de ambas as instituições de forma linear, seguindo os fatos apresentados por todos os entrevistados e documentos coletados. Tecemos uma teia onde se encaixavam a maior quantidade de eventos. Depois, traçamos os pontos em comum das duas histórias, principalmente aqueles que tinham a ver com a influência americana nas mudanças institucionais ocorridas na FEA/USP e na EAESP/FGV. Fizemos praticamente uma "reconstrução" da história das duas instituições de ensino sob outro 
ponto de vista, baseada na influência americana. Também se destaca a contribuição da relação entre as duas escolas, pois ao fazermos analogia ao caminho percorrido por ambas, fomos capazes de apresentar evidências para explicar as diferenças atuais entre as escolas.

O artigo foi elaborado seguindo um modelo historiográfico, adotando a história não necessariamente como ciência, mas mais como um método de pesquisa como já o fizeram diversos autores de Estudos Organizacionais (COOKE, 2003; вOOTH; ROWLINSON, 2006, JACQUeS, 2006; BARROS, 20I3). Há um interesse crescente na organização da teoria historiográfica (CLARK; ROWLINSON, 2004; вOOTH; ROWLINSON, 2006) que podem ser encontrados quando se adota uma abordagem histórica aos Estudos Organizacionais (BURRELL, I997; CLEGG, 2006).

Este artigo une-se ao esforço para consolidação do campo emergente da História da Administração e das Organizações (BOOTH; ROwLinson, 2006; COOKe, 2006, 2007), que difere da História dos Negócios (Business History) por lidar com ideias, práticas e discursos da administração como fenômenos históricos, sociais e geopolíticos. Esta perspectiva afirma que os estudos históricos dizem respeito ao presente e ao passado simultaneamente (COOKE, 2003) E considera a maneira como se escreve a história. Escolhas são necessárias na medida em que eventos são ignorados ou selecionados. A maneira como o historiador modela o passado implica em relações de poder, valores e ideologias que são adotadas, mesmo que apenas implicitamente (COOKE, 1999). A historiografia contribui para a legitimação de instituições, práticas e conjuntos de conhecimentos que são formulados contemporaneamente (COOKE, 2003).

Esta abordagem nega o presente como ele é e que as coisas sejam "naturais" e afirma que são o produto acabado e final de ações e práticas específicas e que poderiam ser de outra forma (JACQUES, 2006). O objeto de pesquisa dos autores só pode ser entendido e analisado no contexto da história nacional e internacional do momento em que a análise é realizada e o conhecimento historiográfico é construído. Portanto, o conhecimento é parte integrante de um contexto sócio-histórico que demanda análise e investigação (MARCH, 2007). Finalmente, esta pesquisa pretende "desnaturalizar" (FOURnIER; 
GREY, 2000) a criação de escolas de administração de empresas no Brasil, mostrando suas relações com o contexto histórico e cultural do momento em que foram criadas, contribuindo para a literatura sobre a criação e a disseminação da educação em administração (ÜsDIKEN, 2004; KHURANA, 2007). 


\section{O CASO DA EAESP/FGV}

A EAESP/FGV teve seu início com uma missão universitária norte-americana (TAYLOR, 1968). Vem a propósito recordar o papel das missões universitárias na criação e expansão de universidades. O que aconteceu na EAESP/FGV tinha precedentes na história universitária brasileira. Duas décadas antes, na mesma cidade de São Paulo, várias missões universitárias atuaram modelando a recém-criada Universidade de São Paulo. A mais importante destas missões foi para a antiga Faculdade de Filosofia, Ciências e Letras que deveria ser o núcleo central da universidade, segundo o modelo escolhido pelos fundadores. Com a devida licença, podemos chamar este modelo de colonial e as tarefas realizadas pelas missões como "colonização", onde os "missionários" transferem práticas e conteúdos da universidade "colonizadora" para o novo núcleo "colonial." Aqui cabe referência a um ensaio escrito por um professor da USP intitulado Um Departamento Francês de Ultramar, que trata do Departamento de Filosofia daquela universidade (ARANTES, I994) e cujo título é manifestamente irônico. Entretanto, o processo missionário não se limitou ao Departamento de Filosofia e situações similares ocorreram nas ciências sociais, nos departamentos de física, química, história e geografia. Também encontramos professores estrangeiros na Faculdade de Medicina da mesma universidade, que tiveram papel decisivo no desenvolvimento da faculdade.

Estas experiências missionárias não se confinaram a São Paulo. Em I935, Anísio Teixeira, Secretário da Educação do então Distrito Federal que era a cidade do Rio de Janeiro, criou a Universidade do Distrito Federal (UDF) e nomeou Afrânio Peixoto como reitor, que por sua vez não hesitou em contratar uma equipe de professores franceses que atuaram em diversas áreas. Portanto, a experiência de contar com uma missão universitária estrangeira para estabelecer universidades ou faculdades foi prática comum no mundo acadêmico (FÁvERO, 2008).

A primeira importante influência do modelo norte-americano sobre a nova escola foi na sua governança. Conforme argumentam Alcadipani e Bertero (20I2), a entidade mantenedora foi desde o início a Fundação Getúlio 
Vargas, mas a EAESP/FGV teve o seu próprio Conselho de Administração, composto por membros indicados pela Fundação Getúlio Vargas e pela International Cooperation Administration (ICA), então uma agência do governo dos Estados Unidos que administrava o auxílio a países em desenvolvimento. Havia também um representante do Ministério da Educação, que neste caso era o diretor da Coordenação do Aperfeiçoamento de Pessoal do Ensino Superior (CAPES) e o que era novo com relação à governança de organizações universitárias: representantes do empresariado. Como nos Estados Unidos, entre outras funções, o Conselho era visto como uma ponte entre a escola e o mundo empresarial. O Conselho ainda desempenhou uma função legitimadora da nova escola e como ligação com o mundo dos negócios, que deveria auxiliar na obtenção de recursos financeiros, como era e ainda é prática nos Estados Unidos. A Fundação Getúlio Vargas tinha expectativas de que a nova escola viesse a ser financeiramente amparada pela comunidade de negócios com contribuições sob a forma de endowments, o que não aconteceu até o momento. E, naturalmente, o Conselho atuou no sentido de estabelecer as diretrizes amplas da escola. Mas o Conselho nunca teve qualquer ingerência na gestão acadêmica da EAESP/FGV que ficou a cargo dos professores norte-americanos (ALCADIPANI; BERTERO, 20I2; TAYLOR, I968).

A influência norte-americana se fez sentir também sobre a estrutura organizacional e os processos administrativos. Conforme mostram Taylor (1968) e Coimbra (2007), a escola adotou desde o início uma estrutura departamental. De acordo com Bertero (2006), a universidade brasileira adotou o modelo da Universidade de Coimbra, ou seja, a universidade se organizava sob a forma de um conjunto de cátedras que eram ocupadas por catedráticos, que constituíam o ápice da carreira docente. Eram aprovados em concurso público de provas e títulos. As cátedras abrangiam amplas áreas de conhecimento. Muitas vezes a abrangência de uma cátedra poderia evocar até a multidisciplinaridade dos dias atuais. As cátedras foram abolidas e em seu lugar surgiram os departamentos. Por vezes uma cátedra passava a constituir um departamento, mas não automática e nem necessariamente. Uma cátedra também poderia gerar mais de um departamento. No regime 
de cátedra era fundamental que se considerasse o poder detido pelo professor catedrático. Sem exagero, o regime de cátedras equivalia a uma monarquia absoluta na academia. O professor catedrático tinha o poder de administrar um orçamento, admitir, demitir e avaliar os professores que eram todos considerados seus assistentes. E para coroamento, sua posição era vitalícia.

Devido à influência da missão da MSU, a EAESP/FGv já começou estruturada em forma departamental, onde cada departamento de ensino e pesquisa tinha um chefe, designado pelo diretor da escola com base em uma lista tríplice eleita pelos professores do departamento respectivo (COIMBRA, 2007). Os departamentos seguiram a estrutura departamental de uma escola norte-americana de negócios que acompanhavam as áreas funcionais de administração de negócios. Desta maneira, desde o início, os departamentos foram os de marketing, contabilidade, finanças, produção operações e assim por diante (TAYLOR, 1968). A extinção das cátedras e a adoção do departamento como unidade fundamental de ensino e pesquisa só vieram a ser instituídas na universidade brasileira pela Lei Federal $\mathrm{n}^{\circ}{ }^{\circ} .540$ de $\mathbf{1 9 6 8}$, mais conhecida como lei da reforma universitária.

A mais clara e marcante influência norte-americana na EAESP/FGv foi no currículo de graduação, iniciado em $1955 \mathrm{com}$ a primeira turma graduandose em 1958, com duração de quatro anos e dividido em oito semestres (TAYLOR, 1968). O currículo baseava-se em programas similares oferecidos à época na maioria das escolas norte-americanas de administração de empresas e seguindo mais de perto o que se ensinava na MSU.

De acordo com Taylor (1968) e Coimbra (2007), o programa baseava-se em ciências sociais. Havia introdução à economia, com cursos em moeda, crédito e bancos, teoria macro econômica, economia internacional e economia brasileira. O mesmo ocorria com sociologia e psicologia, havendo cursos introdutórios em psicologia e sociologia voltados às aplicações em administração. Também podem ser encontrados no currículo de 1955 dois cursos de Ciência Política e disciplinas consideradas instrumentais para a administração como matemática, estatística, contabilidade e pesquisa operacional. O direito era também ensinado em suas diversas ramificações como comercial, trabalhista, previdenciário, fiscal e tributário. É interessante 
registrar que no segundo semestre de um currículo de 1955 ensinava-se no sexto semestre um curso chamado Processamento de Dados. A Tecnologia de Informações de então ainda vivia a sua infância e a micro informática surgiria somente três décadas adiante.

Segundo Taylor (1968), no primeiro semestre havia um curso de Introdução à Administração de Empresas, mas os cursos de administração só começavam no quinto semestre. Os quatro primeiros semestres poderiam ser entendidos como propedêuticos. A partir do quinto semestre eram ministrados os cursos que seguiam as diversas áreas funcionais de administração como eram chamadas naquela época e que surpreendentemente não sofreram grandes modificações desde então. Apenas no início do século xxi é que algumas críticas começaram a surgir contra a compartimentalização da administração em áreas funcionais e passaram a aparecer tentativas de integração das diversas áreas com apoio na multidisciplinaridade. Cursos que eram ensinados no currículo de 1955 eram designados como Marketing, Administração do Pessoal, Administração Financeira e Orçamentos, Administração de Vendas, Administração da Produção, Organização e Relações Humanas e Diretrizes Administrativas ou simplesmente Estratégia de Negócios (Business Policy).

O que chama em particular a atenção neste currículo elaborado em I955 foi a sua longevidade e o quanto influenciou não apenas a EAESP/ FGV, mas escolas de administração em todo o país e serviu de base para a regulamentação do curso universitário em administração (BERTERO, 2006). Até hoje, cursos de graduação em administração manifestam em seus currículos e conteúdos programáticos o que foi inicialmente proposto em 1955. Atualmente há várias iniciativas para rever e reformular cursos de graduação, mudando, modificando, complementando ou rejeitando, mas sempre tendo o tradicional currículo como referência.

Foi também iniciado um curso de pós-graduação. Na época, essa era uma prática totalmente desconhecida na universidade brasileira e tampouco usada como forma de preparar ou reciclar profissionais. Com esta primeira experiência de pós-graduação, a missão da MSU pretendia replicar aqui o que na época era o Master of Business Administration (мва) 
norte-americano. Conforme Coimbra (2007), foi oferecido em regime de tempo integral e todos os alunos receberam bolsas de manutenção. As aulas eram ministradas por professores da missão e o conteúdo programático era também um transplante do que se ensinava nos MBAs dos Estados Unidos. A primeira tentativa foi em 1958 sem grande sucesso. Houve poucos candidatos e apenas sete pessoas chegaram ao final (TAYLOR, I968). O curso foi oferecido novamente em I96I com bolsas para os alunos o que fez com que aumentasse o número de interessados. Desde então, o curso consolidou-se com o objetivo de oferecer a pessoas que não tinham estudado administração na graduação uma formação na mesma. Foi com base neste curso que outros cursos de pós-graduação foram desenvolvidos na EAESP/ FGV (TAYLOR, I968), efetuando-se as necessárias adaptações à realidade brasileira e especialmente atendendo à legislação de 1965 que dividia a pósgraduação em stricto e lato sensu.

Ainda sobre a influência exercida pela EAESP/FGV no delineamento de currículos de administração nas diversas áreas é oportuno registrar que a escola iniciou suas atividades em 1954 com um curso direcionado para executivos e empresários (TAYLOR, I968; COIMBRA, 2007). Tratava-se do Curso Intensivo de Administração (CIA) que durava treze semanas em regime de tempo integral sendo estruturado ao redor de cinco áreas funcionais: Atividades Administrativas, Contabilidade e Administração Financeira, Distribuição e Vendas, Produção e Legislação Brasileira de Negócios. O curso foi uma inovação no Brasil e marcou o início das atividades de ensino que posteriormente receberam a designação de Educação Executiva. Com esse curso, a EAESP/FGV buscava atingir uma clientela de empresários e executivos com o objetivo de abrir caminho para o desenvolvimento da profissão de administrador.

A última influência norte-americana a ser registrada vinculava-se à maneira como se recrutaram e selecionaram os professores para a nova escola. No Brasil de então, professores universitários atuavam quase que exclusivamente em universidades públicas onde o provimento de cargos docentes era feito mediante concursos públicos de provas e títulos. Isto se aplicava apenas aos professores catedráticos. Os demais professores, todos 
designados como assistentes, eram nomeados pelo catedrático. De acordo com Taylor (1968), a EAESP/FGV teve os seus primeiros professores recrutados no mercado de trabalho por meio de anúncios onde os candidatos eram selecionados exclusivamente pelos critérios adotados pela missão da MSU, preferencialmente pessoas em início de carreira no mundo empresarial. Tais candidatos eram admitidos e submetidos a um treinamento prévio no país, antes de serem enviados aos Estados Unidos para realizar um mestrado, na época um мва.

Como se pode ver, a influência da missão universitária norte-americana foi decisiva e introduziu diversas inovações. Naturalmente o seu impacto foi grande e a gestão acadêmica permaneceu inteiramente nas mãos dos professores da missão, sem que a Fundação Getúlio Vargas tivesse maior interferência acadêmica no novo projeto.

\section{O CASO DA FEA/USP}

A fea/usp é uma faculdade da Universidade de São Paulo, e segundo Fausto (1995) foi a primeira universidade brasileira.

Mais abrigada das tempestades políticas e implantada com maior solidez pela elite paulista, a USP não só sobreviveu como se tornou o principal centro de ensino e pesquisa do país. Sua criação decorreu, por um lado, da existência na capital paulista, desde a Primeira Guerra Mundial, de um vivo debate das principais questões educacionais, com propósitos reformadores; por outro, do fato de os principais participantes desses debates, com Fernando de Azevedo à frente, terem firmado posições no aparelho de ensino paulista até o golpe de 1937 (FAusto, 1995, p. 338).

A FEA/Usp foi criada em 1946 como uma faculdade de economia e contabilidade, mas o curso de graduação em administração só foi iniciado em 1964 (BERTERO, 2006). A universidade, conforme exposto anteriormente, se estruturava tendo a cátedra como unidade básica (TAYLOR, I968). A criação de um Departamento de Administração na FEA/usP deveu-se às iniciativas de dois professores da Escola Politécnica: Ruy Aguiar da Silva Leme e Sergio Baptista Zaccarelli nos anos de 1960. Há um livro que foi escrito pelo professor Ruy Leme, conforme mencionado na metodologia desse 
artigo, que defendia veementemente que era necessária uma reformulação quase que total e voltada para o mercado de trabalho dos cursos oferecidos pela FEA/UsP. Tal livro foi financiado pela CAPES e também pelo Ponto iv e usou como inspiração a viagem que uma comissão de professores da FEA/ usp fez no ano de 1959 a diversas instituições que ensinavam Management nos Estados Unidos (LEME, I960). Há um agradecimento explícito ao Ponto Iv, que nada mais foi que uma ajuda econômica americana aos países subdesenvolvidos durante o governo Truman para que não fossem influenciados pelos comunistas (NOGUEIRA, I999). A seguir, o agradecimento de Ruy Leme:

Em primeiro lugar, sob o título "EXPERIÊNCIA AMERICANA NO ENSINO DA ADMINISTRAÇÃO" resumimos algumas observações feitas por ocasião de nossa visita às Universidades: Estadual de Michigan, Purdue, (...), visita esta feita sob os auspícios do Ponto iv e da CAPES nos princípios do ano de 1959 (LEME, 1960, apresentação).

É importante registrar que a Escola Politécnica foi criada por leis estaduais em I893, com grande influência europeia. Setenta anos depois, quando se tratou de adotar um programa de administração de negócios, os olhos e a busca se voltaram para os Estados Unidos, como fonte de inspiração de conteúdo programático para os cursos (BERTERO, 2006).

Diferentemente do que aconteceu com a EAESP/FGV, a FEA/USP não recebeu apoio direto do governo norte-americano e de fundações dos Estados Unidos, entretanto, em uma de nossas entrevistas fomos lembrados de que houve praticamente uma "revolução" da teoria econômica nos Estados Unidos e que muitos dos professores da faculdade de economia foram fazer seus doutorados naquele país por conta disso, gozando de bolsa dada pela United States Agency for International Development (USAID). A seguir, trecho de entrevista concedida pelo professor Hélio Nogueira da Cruz:

Houve um programa de intercâmbio internacional de professores, que foi muito importante para a área de ciências econômicas no país e na FEA/usP. Vieram muitos professores americanos de altíssimo padrão e foram enviados muitos alunos, que mais tarde se tornariam docentes, para universidades americanas de primeira linha, como Harvard, Yale e Chicago. Olhando hoje, 
percebemos como foi excepcional aquele período. Foi uma guinada. A FEA optou decididamente pela ortodoxia do mainstream. Passamos a contar com um grande número de docentes em período integral, que passavam a publicar em periódicos internacionais. Desde o início dos anos 1960, o Departamento de Economia e a FEA tiveram papel de destaque no país. Delfim Netto, Affonso Pastore e Ruy Leme, acabaram por facilitar a obtenção de recursos para montar um Centro de Processamento de Dados bastante significativo para os padrões da época. A FEA, desde então, tem apresentado contribuição significativa na extensão universitária, com expressiva participação no debate econômico nacional e grande número de docentes que ocuparam relevantes posições no Governo, em suas várias esferas de atuação (мотоунма, 2006, p. 368).

Além disso, encontramos, nas atas da Congregação indicações de alguma forma de auxílio provinda dos Estados Unidos. Durante o ano de 1964 o professor Dorival Vieira teria assegurado recursos do Ponto IV e da Fundação Ford para enviar aos Estados Unidos doutorandos para conclusão de seus programas de estudo. O acordo com a Fundação Ford foi assinado pelo então diretor, imediatamente após a criação do Instituto de Pesquisas Econômicas (IPE), posteriormente transformado em Fundação Instituto de Pesquisas Econômicas (FIPE). A discussão sobre a criação do IPE e o recebimento do auxílio norte-americano foi bastante acalorada, incluindo uma ameaça de renúncia do professor Antonio Delfim Netto. É interessante observar que o auxílio foi recebido pelo Departamento de Economia. Embora na época estes legalmente ainda não existissem, o termo Departamento já era correntemente encontrado nos documentos da FEA/USP.

A intenção de se criar na FEA/Usp um Departamento de Administração pode ser encontrada antes da década de 1960. Um Departamento de Administração de Empresas fazia parte do projeto de criação da Faculdade de Ciências Econômicas. A Universidade de São Paulo foi fundada em 1934 e o então Secretário da Educação do Estado de São Paulo, Cristiano Altenfelder Silva, afirmava que os pilares do conhecimento na universidade recémcriada deveriam situar-se numa Faculdade de Economia e Administração (моточАма, 2006). 
É por isso que a criação e o funcionamento desde logo na Universidade de São Paulo, em 1934, da Faculdade de Filosofia, Ciências e Letras, estabelecida com a orientação de dar ao ensino o cunho científico e de tornar possível a preparação do professorado secundário, ao lado de outro instituto de alta cultura que será a Faculdade de Ciências Econômicas e Comerciais, realizarão, efetivamente, os fins da Universidade, que aliam à formação de profissionais e de especialistas em todos os ramos de cultura, a transmissão, pelo ensino, do conhecimento (SILVA, I937 apud мотоуама 2006, p. 25).

Ainda na vigência do regime de cátedras foi criada uma cadeira de Ciência da Administração, porém, estava ligada ao curso de ciências econômicas e administrativas. $O$ catedrático era o professor José Reis que também era diretor do Instituto de Administração (IA). O IA não integrava a universidade e herdara o que restara do Departamento do Serviço Público do Estado de São Paulo (DSP). O IA tinha como finalidade o que na época se chamava de "racionalização" da administração pública estadual, à semelhança do Departamento Administrativo do Serviço Público (DASP) estabelecido a nível federal, em i938. O departamento paulista recebeu influências do serviço público inglês, francês e norte-americano e o poder do professor José Reis era considerável ao acumular a cátedra e a direção do IA (NOGUEIRA, I984). Esse instituto incluía um corpo de funcionários em regime de tempo integral, uma biblioteca e todas as instalações que vieram do DSP. O Instituto chegou a ter um contingente de funcionários maior do que a própria FEA/USP. Era inevitável que surgissem atritos, e, em I946, o professor José Reis acabou sendo afastado pelo fato de ter sido nomeado sem passar por concurso público de provas e títulos. A esta altura a FEA/ usp cedeu às pressões pela criação de mais vagas, o que incluía também, e contraditoriamente a saída do professor José Reis, já que tais cargos eram justamente para nomeação de novos professores (PINHO, I984).

Mais de uma década após sua criação, a FEA/usp decidiu iniciar cursos de administração, o que não foi uma decisão fácil porque na época, a instituição enfrentava uma crise devido à reduzida procura de seus cursos de economia e contabilidade. Segundo Pinho (1984), a instituição enfrentava essa situação porque não preparava profissionais aptos para atuar no 
mercado de trabalho àquela época, o que fazia que além da baixa procura, os cursos tivessem altos índices de desistência. Em 1959, matricularamse na faculdade aproximadamente quarenta alunos e apenas treze se graduaram (CANABRAVA, 1984). O professor Antonio Delfim Netto defendia a criação de cursos de graduação em administração para evitar que a FEA/ USP perdesse relevância no contexto da Universidade (O CANGURU, 1957). Abaixo, transcrição de parte do discurso do paraninfo da turma de 1956, o próprio professor Antonio Delfim Netto:

Concretamente, acredito que deveríamos dar maior atenção à formação de administradores, pois, é neste setor que o mercado de trabalho está crescendo mais rapidamente. Temos, em minha opinião, deixado de reconhecer a profunda diferença que existe entre as necessidades de formação de um economista ou de um contador e de um administrador. Ouso mesmo dizer que neste grave erro se encontra o cerne das agitações e dificuldades pelas quais está passando a Faculdade. É aqui que se encontra a origem daquela insatisfação do abstrato de que vos falei há pouco.

(...)

Os cursos desenvolvidos na Faculdade não cobrem, infelizmente, aquela parcela de "ciências administrativas" que lhe serve de nome. Aqueles que a procuram em busca de um curso de administração, isto é, de um curso que os habilite a empregar, com sucesso, as suas energias no campo interno das empresas ou do serviço público, sofrem à medida que o curso se desenvolve (...) o que cria grandes problemas para o aluno. O erro decorre, de um lado, de figurar como título da Faculdade alguma coisa que ela não pode realmente proporcionar e, de outro, do quase completo desconhecimento do papel do economista dentro da sociedade moderna.

(...)

Enquanto não instituirmos, na Faculdade, cursos nas quatro especializações: economia, administração, contabilidade e atuária, não conseguiremos, realmente, torna-la mais forte e mais fiel a si mesma. A nossa Faculdade sofre a amargura daqueles que não conseguiram realizar-se plenamente $(\mathrm{O}$ CANGURU, I957, p. I3-I6). 
Alunos da FEA/USP já vinham se manifestando pela criação de cursos que fossem "mais práticos e aplicados" do que os cursos tradicionais de economia ensinados na faculdade. Havia pressões por mudanças na universidade como um todo e os alunos enviaram uma carta ao diretor da faculdade queixando-se das dificuldades que encontravam no mercado de trabalho quando saíam do curso e sobre as transgressões dos professores que não respeitavam o período integral de dedicação à faculdade. A carta, de I955, com as queixas foi assinada por Álvaro Armando Leal e Maurício Vaena, representando os alunos, ex-alunos e o centro acadêmico da FEA/ USP. Isto se devia fundamentalmente ao fato de que o mercado demandava mais administradores do que economistas tradicionalmente formados. Então, diferentemente do que acontece hoje, os cursos de economia não eram voltados à preparação de pessoas que atuariam no mercado financeiro. Adicionem-se a isto as demandas por reforma da universidade enfatizando a necessidade de se abolir o regime de cátedras (NOGUEIRA, I984).

Naquele momento, o professor Ruy Leme trabalhava com professores da missão da MSU na Escola Politécnica, o que nos foi lembrado durante uma de nossas entrevistas concedidas durante a pesquisa. A ideia inicial seria uma aproximação e um intercâmbio entre os professores que atuavam na EAESP/Fgv e aqueles da Escola Politécnica, onde se planejava criar um curso de Engenharia da Produção. Conforme lembrado por nosso professor entrevistado, inicialmente o professor Ruy Leme anunciou um encontro na Politécnica onde os professores daquela escola e os da MsU apresentariam suas sugestões e dialogariam com os interessados na criação de um novo curso. O convite foi publicado na imprensa e a afluência foi tão grande que se tornou impossível acomodar todos. O próprio Ruy Leme pegou os contatos dos interessados para tentar fazer um novo evento que conseguisse acomodar a todos.

Logo após este evento, Ruy Leme recebeu um convite da FEA/UsP para que auxiliasse na reforma e revisão de seus cursos. Conforme dito anteriormente, em 1959, Ruy Leme foi para os Estados Unidos com uma comissão de professores para visitar as seguintes escolas de administração e negócios: Estadual de Michigan, Purdue, Chicago, Pittsburgh, Carnegie Tec, 
Cornell, Harvard, MIT, Columbia, New York, City College e Pennsylvania. O primeiro produto da viagem foi um livro (LEME, 1960) onde se descrevia a experiência educacional norte-americana em administração de empresas e também se sumariavam as impressões colhidas pela comissão em sua visita às várias escolas já citadas. $\mathrm{Na}$ época se discutia sobre a necessidade de cursos para formação de administradores (TAYLOR, I968). A fim de esclarecer a questão, Ruy Leme (LEME, 1960) descrevia o que cada profissional deveria fazer no mercado de trabalho e esclarecia quais as diferenças entre o administrador e o economista. O objetivo era convencer os leitores de que era perfeitamente normal e aceitável que administradores fossem treinados na mesma escola ao lado de economistas e contadores. Além disso, Leme (1960) seguia a linha de pensamento exposta pelo professor Delfim Netto no jornal editado pelo Centro Acadêmico Visconde de Cairu (c.A.v.c.), O Canguru (1957), onde era defendido que outros cursos fossem criados, além daqueles que já eram oferecidos. Ademais, a reestruturação didática da FEA/USP foi efetivamente feita com o decreto $n^{\circ}$ 36.36I de 8 de março de 1960. O mercado de trabalho estava longe de estar saturado e absorveria sem problemas todos estes profissionais.

Após a visita da comissão de professores aos Estados Unidos e de baixado o decreto, desencadeia-se, de fato, uma reforma na faculdade em $1960 \mathrm{com}$ o objetivo de superar a crise acima referida. O caminho encontrado, além de investir em cursos para os professores, preferencialmente no exterior, e na reestruturação dos cursos de graduação, foi iniciar um curso de pósgraduação em administração porque a profissão de administrador ainda não havia sido regulamentada por lei no país (LEME, 1960). A predileção por um curso de pós-graduação foi explicada por uma entrevista concedida em 1975 pelo professor Dorival Vieira: "Sendo a Universidade de São Paulo um estabelecimento de ensino superior oficial, preferiu-se não se implantar na Faculdade de Ciências Econômicas e Administrativas cursos que graduassem bacharéis para o exercício de uma profissão, ainda não regulamentada por Lei." (TOLEDO; TREVISAN, 1984, p. 7I). Vale lembrar aqui que a profissão de administrador só foi regulamentada em 1965. Assim, os primeiros semestres lançavam as bases com cursos de matemática, 
contabilidade, história e geografia, economia, direito, ciências sociais e estatística. Apenas depois é que disciplinas de gestão de negócios eram ministradas. As especializações vinham ao final do curso onde a escolha deveria ser feita entre Administração Pública e Administração de Empresas. Caso escolhessem Administração de Empresas, deveriam ainda optar por produção, administração do pessoal, mercados ou finanças. Os diplomas ainda eram conferidos em economia, mas o conteúdo cursado pelos alunos incluía administração, caso eles assim tivessem optado.

Este curso ainda foi oferecido pela FEA/USP até 1964, quando se iniciou o curso de graduação efetivamente. O início do novo curso coincidiu com o golpe de Estado que abriu o longo período de governos militares que só terminaria nos anos de i980. A ideologia adotada pelo governo militar implicou em repressão e perseguição àqueles que fossem considerados como sendo de "esquerda". No mundo universitário, isto acarretou em afastamentos e aposentadorias compulsórias de muitos professores. Um distinguido professor da FEA/USP, Wagner Vieira da Cunha acabou tendo que ceder às posições que ocupava na universidade, fato lembrado em mais de uma das entrevistas feitas com os professores da FEA/usp. Wagner, com reconhecida formação "humanista" foi substituído por Sergio Zaccarelli que era competente profissional e acadêmico, mas com um perfil mais técnico, "passando" pelo filtro ideológico do governo. O departamento de administração da FEA/USP passou a abrigar diversos engenheiros, por força dos vínculos iniciais com professores da Escola Politécnica. Os professores Sergio Zaccarelli e Ruy Leme eram professores da Escola Politécnica e passaram a exercer atividades também na FEA/USP.

Paradoxalmente, a FEA/UsP acabou tendo um relacionamento menos problemático com o regime militar do que a EAESP/FGV. Enquanto uma escola se estabelecera com a interveniência de uma missão universitária norte-americana, seu relacionamento com o regime militar chegou a ter momentos difíceis, ao passo que a FEA/UsP tinha um perfil mais técnico que fez com que alguns de seus professores chegassem a participar do governo militar. Mesmo assim, alguns alunos da FEA/UsP acabaram desaparecendo durante o governo militar e até o ex-presidente do c.A.v.c., Paulo Beskow, 
foi preso e torturado. Esses fatos foram lembrados em algumas de nossas entrevistas e, além disso, encontramos algumas citações nas atas da congregação sobre os alunos desaparecidos nessa época. A figura mais notória e destacada da FEA/USP que participou do governo militar foi o professor Antonio Delfim Netto que ocupou o Ministério da Fazenda, em 1967, durante o governo do Presidente Costa e Silva, permanecendo na pasta até o governo do Presidente Emílio Garrastazu Médici, além disso, foi embaixador em Paris, de 1975 a 1978, voltando no ano seguinte para ser Ministro da Agricultura e depois Ministro-Chefe da Secretaria de Planejamento da Presidência da República. Além dele, o professor Ruy Leme foi um dos primeiros presidentes do Banco Central do Brasil, ocupando o cargo entre os anos de 1967 e seguinte. (FACULDADE DE ECONOMIA, ADMINISTRAÇÃO E CONTABILIDADE DA UNIVERSIDADE DE SÃO PAULO, 2008).

O curso de administração da FEA tinha uma orientação mais prática ou managerial sem a presença de um departamento de Ciências Sociais com predominância de professores de esquerda, como acontecia com a EAESP/ FGV, embora isto não possa ser atribuído ao estabelecimento no país de um regime militar de orientação claramente nacionalista e de direita. 


\section{DISCUSSÃO E CONCLUSÕES}

A importância em comparar ambas as escolas deve-se ao fato de que foram as portas de entrada para o modelo norte-americano de administração (Management) e as duas tiveram um papel decisivo na difusão da educação em administração no país. Tanto uma quanto outra se tornaram centros importantes por meio de seus cursos de pós-graduação para o treinamento e desenvolvimento de professores para outras instituições brasileiras de ensino superior, incluindo docentes do sistema universitário federal.

A EAESP/FGV mereceu a preferência indiscutível dos americanos como ficou claro pelo montante gasto no projeto e também pela manutenção de uma missão universitária por mais de dez anos. E a Fundação Getúlio Vargas não é menos merecedora de reconhecimento pelo sucesso do projeto na medida em que atuou sempre como entidade mantenedora e foi importante pioneira num projeto que hoje chamaríamos de empreendedorismo acadêmico ao alinhar e agregar os diversos atores para que o projeto se viabilizasse.

Todavia, a preferência dada ao projeto da EAESP/FGV não foi impedimento para que a FEA/USP também se desenvolvesse como importante centro, dada a importância que a USP já tinha e continua tendo como a primeira universidade brasileira.

As semelhanças encontradas nas duas instituições não chegam a ocultar diferenças merecedoras de atenção. O ensino e a pesquisa em administração chegaram à FEA/USP por um caminho mais tortuoso. A faculdade onde se instalaria a área de administração tinha na década de 1950, três cátedras que posteriormente se tornariam departamentos: Economia, Contabilidade e Administração. Até então, no âmbito da USP, administração era entendida como sendo administração pública, conhecimento que decorreu do IA, que por sua vez, deveria apoiar a reforma da administração pública do Estado de São Paulo por meio de projetos de consultoria. A tradição da administração pública italiana e francesa ainda considerava a contabilidade como integrando a administração, pela tradição e importância dos Tribunais de Contas que se estabeleceram no país com a república e que é órgão fundamental para a auditoria das contas públicas. Desta maneira, a 
cátedra de contabilidade naturalmente resistia à expansão de uma cátedra de administração pela introdução de administração de empresas ou de negócios, adotando uma perspectiva norte-americana.

Os professores da missão universitária da MSU moveram-se com facilidade não só no âmbito da FGv, mas também na usp. Mas é interessante e inteligível que tenham encontrado maior receptividade não na FEA/USP primeiramente, mas na Escola Politécnica e lá mais particularmente na área de Engenharia da Produção, que acabou cedendo diversos professores à FEA/USP quando se decidiu por uma renovação e ampliação da Cátedra e posterior Departamento de Administração.

As mudanças ocorridas na FEA/USP alteraram a importância relativa dos três departamentos. O de Contabilidade inegavelmente perdeu parte da influência que tivera durante as duas décadas precedentes e o de Administração ergueu-se a uma condição de paridade com o já prestigiado Departamento de Economia. Mas o desenvolvimento do Departamento de Administração da FEA/usp diferia bastante do que se desenvolveu na EAESP/FGV.

A influência dos professores de engenharia como os líderes da mudança na FEA/USP teve consequências nos conteúdos programáticos dos cursos e na orientação geral do projeto de Administração na FEA/usp. Pode-se dizer que em muitos países, engenheiros são vistos como matéria prima de excelente qualidade para administradores. A profissão de engenheiro é mais antiga do que a de administrador na maioria dos países e até nos dias atuais engenheiros detêm boa parte das posições administrativas tanto no mundo empresarial como na administração pública. Engenheiros são profissionalmente treinados e socializados paras serem solucionadores de problemas, o que assegura o desenvolvimento de habilidades intelectuais que os orientam à prática. "Dê-me um problema que eu lhe darei a solução", poderia ser um refrão para a profissão de engenheiro. Por esta via, o programa desenvolvido na $\mathrm{FEA} / \mathrm{USP}$ sempre foi mais inclinado à prática do que o que se desenvolveu na EAESP/FGv. Pode parecer paradoxal que uma escola de administração, onde uma missão de professores norteamericanos controlaram academicamente a elaboração dos programas 
durante os primeiros dez anos, tenha se tornado um local mais aberto a uma abordagem crítica da administração (Management) e com menor ênfase de tipo gerencialista (managerial). Na FEA/Usp houve uma influência norteamericana, trazida pela comissão de professores que visitaram diversas escolas americanas de administração de negócios, mas esta influência foi mediada pelo fato de que eram professores de engenharia.

A influência norte-americana veio do contato dos professores da usP que foram visitar escolas de negócios nos Estados Unidos em busca de elementos que pudessem utilizar na reorganização de um Departamento de Administração da FEA/usp que pudesse fazer com que a crise advinda da falta de alunos e do aumento da desistência discente sumisse já que ao que parecia, o mercado de trabalho procurava profissionais àquela época com habilidades diferentes daquelas que a FEA/USP preparava seus formandos. Mas nunca houve o impacto que as ciências sociais exerceram na EAESP/FGv. Embora o Departamento de Ciências Sociais da usp tenha ocupado uma posição de liderança nas ciências sociais entre os anos de 1950 e 1980, onde professores como Fernando de Azevedo, Florestan Fernandes, Otavio Ianni e Fernando Henrique Cardoso atuaram, ele não chegou a influenciar o Departamento de Administração da FEA/USP. A orientação predominante no Departamento de Administração, pelos padrões da época, era claramente mais à direita do que a que se encontrava no Departamento de Ciências Sociais da USP e também na EAESP/FGV.

Como já mencionado neste artigo, o professor Antonio Delfim Netto foi ministro poderoso e influente da área econômica durante o mandato de três dos presidentes generais que o país teve durante o regime militar. O professor Ruy Aguiar da Silva Leme, figura central na reorganização do Departamento de Administração e também do Departamento de Engenharia da Produção da Escola Politécnica, sempre com inspiração norte-americana, foi presidente do Banco Central do Brasil também na vigência do regime militar. A Fundação Getúlio Vargas teve igualmente envolvimento com o regime militar, talvez até mais profundamente do que a FEA/USP, mas tal envolvimento foi de professores de outras escolas e unidades da Fundação, mas nunca da EAESP/FGv. Esta se manteve distante 
do regime militar chegando a abrigar professores perseguidos pelo regime e movimentos estudantis claramente hostis ao regime. Um exemplo que equivaleria ao envolvimento de professores da FEA/usp foi o de Mario Henrique Simonsen, ministro de dois dos presidentes do regime militar, ministro da fazenda e do planejamento entre 1974 e 1985 . Era professor e diretor da prestigiada Escola de Pós Graduação de Economia da Fundação Getúlio Vargas (EPGE/FGV).

Outra diferença a separar as duas escolas foi a tendência ao chamado inbreeding ou endogenia, na admissão de professores que era praticado pela $\mathrm{FEA} / \mathrm{USP}$, seguindo a prática da própria USP e da maioria das universidades brasileiras na época. Apenas excepcionalmente professores da usP eram portadores de graus obtidos, particularmente doutorados, em universidades estrangeiras. Muitos faziam estágios no exterior e frequentavam algumas disciplinas em universidades estrangeiras, mas por um período limitado que ia de um semestre a um ano. Mas o grau era conferido pela USP o que implicava em uma tese aqui redigida e avaliada por banca constituída pela universidade. O resultado era um corpo docente formado de ex-alunos da usp e que tinham cursado naquela universidade a graduação, o mestrado e o doutorado. A EAESP/FGv selecionou seus jovens professores que desejavam iniciar uma carreira acadêmica, por processo inteiramente diferente e que era absolutamente distante das práticas brasileiras. A missão universitária americana foi ao mercado e buscou pessoas que desejavam entrar na carreira acadêmica, mas que não possuíam ainda experiência alguma. Teriam que ser inteiramente treinados. A missão estava ciente do risco, mas mesmo assim optou por esta solução. O resultado, de maneira geral, mostrou-se bem sucedido com poucos casos de insucesso que terminaram na demissão de alguns e pela perda de outros que por iniciativa própria, após alguns anos, desistiram da carreira acadêmica, indo ao mercado de trabalho como profissionais de administração.

Apesar das diferenças, ambas as escolas vieram a desempenhar papel importante no Brasil e em algumas nações latino-americanas que se tornaram centros de difusão para a expansão do modelo norte-americano de administração. Podemos dizer, então, que a Americanização da EAESP/ 
FGV foi mais direta, enquanto da FEA/USP foi um processo mais indireto e com menor influência explícita dos Estados Unidos. Até que ponto a EAESP/ FGV e a FEA/USP podem ser consideradas escolas norte-americanas fora dos Estados Unidos é outra questão e merecedora de uma resposta. As duas escolas, sem sombra de dúvidas, receberam influência norte-americana, embora de maneira diversa. Mas esta e aquela acabaram desenvolvendo projetos e adquiriram perfis diferentes, que até hoje se mantêm distintos. São duas escolas com duas identidades, indicando que pode haver formas distintas de Americanização, até mesmo em um mesmo país e em uma mesma cidade. 


\section{REFERENNCIAS}

ALCADIPANI, R.; BERTERO, C.O. Guerra fria e ensino do management no Brasil: o caso da FGV-EAESP. Revista de Administração de Empresas, v. 52, n. 3, p. 284-299, 2012.

ALCADIPANI, R.; CALDAS, M.P. Americanizing Brazilian management, Critical Perspectives on International Business, v. 8, n. 1, p. 37-55, 2012.

ARANTES, P.E. Um Departamento Francês de Ultramar: estudos sobre a formação da cultura filosófica uspiana (uma experiência nos anos 60). Rio de Janeiro: Paz e Terra, 1994. $316 \mathrm{p}$.

ATKINSON, P.; COFFEY, A. Analysing Documentary Realities. In: SILVERMAN, D. Qualitative research: theory, method and practice. London: Sage, 1998. cap. 5, p. 77-92.

BAER, W. A economia brasileira. São Paulo: Nobel, 2009.

BARROS, A.N.de. Uma narrativa sobre a história dos cursos de administração da FACEUFMG: às margens do mundo e à sombra da FGV? 2013. Tese (Doutorado em Administração) - Universidade Federal de Minas Gerais, Belo Horizonte, 2013.

BERTERO, C.O. Ensino e Pesquisa em Administração. São Paulo: Thomson, 2006.

BOOTH, C.; ROWLINSON, M. Management and organizational history: prospects. Management \& Organizational History, v.1, n. 1, p. 5-30, 2006.

BRASIL. Lei $n^{\circ}$ 5.540, de 28 de novembro de 1968. Fixa normas de organização e funcionamento do ensino superior e sua articulação com a escola média, e dá outras providências. Diário Oficial [da] República Federativa do Brasil, Brasília, DF, 23 nov. 1968 e 3 dez. 1968. Disponível em: <http://www.planalto.gov.br/ccivil_03/leis/15540. htm >. Acesso em: 05/02/2013.

BRASIL. Lei $n^{\circ} 4.769$, de 9 de setembro de 1965. Dispõe sobre o exercício da profissão de Técnico de Administração, e dá outras providências. Diário Oficial [da] República Federativa do Brasil, Brasília, DF, 13 set. 1965. Disponível em: $<$ http://www.planalto. gov.br/ccivil_03/leis/14769.htm>. Acesso em: 05/02/2013.

BURRELL, G. Pandemonium: towards a retro-organization theory. London: Sage, 1997.

CANABRAVA, A.P. (Org.). História da Faculdade de Economia e Administração da Universidade de São Paulo 1946/1981: v. 2. Personália. São Paulo: A Faculdade, 1984.

CARDOSO, F.H.; FALETTO, E. Dependência e desenvolvimento na América Latina: ensaio de interpretação sociológica. Rio de Janeiro: Civilização Brasileira, 2004.

CLARK, P.; ROWLINSON, M. Time and narrative history: chattering historical narratives. Academy of Management Meeting, Organization and Management History Division, Denver, August, 2004.

CLEGG, S. The bounds of rationality: power/history/imagination. Critical Perspectives on Accounting, v. 17, n. 7, p. 847-863, 2006.

COIMBRA, C.J. FGV EAESP: 50 Anos. São Paulo: Via Impressa, 2007. 
COOKE, B. The Kurt Lewin/Goodwin Watson FBI/CIA files: a 60th anniversary thereand-then of the here-and-now. Human Relations, v. 60, n. 3, p. 435-462, 2007.

COOKE, B. The Cold War origin of action research as managerialist cooptation. Human Relations, v. 59, n. 5, p. 665-693, 2006.

COOKE, B. The denial of slavery in management studies. Journal of Management Studies, v. 40, n. 8, p. 1895-1918, 2003.

COOKE, B. Writing the left out of management theory: the historiography of the management of change. Organization, v. 6, n. 1, p. 81-105, 1999.

CURADO, I.B. Pesquisa historiográfica em administração: uma proposta metodológica. In: EnANPAD, 25., 2001. Campinas. Anais...Campinas: Anpad, 2001.

D’ARAUJO, M.C. Fundação Getúlio Vargas: Concretização de um ideal. Rio de Janeiro: FGV, 1999.

FACULDADE DE ECONOMIA, ADMINISTRAÇÃO E CONTABILIDADE DA UNIVERSIDADE DE SÃO PAULO. Vídeos | FEA-USP. [S.I.]: c2008. Disponível em $<$ http://www.fea.usp.br/video.php >. Acesso em: 12/12/2011.

FACULDADE DE ECONOMIA, ADMINISTRAÇÃO E CONTABILIDADE DA UNIVERSIDADE DE SÃO PAULO. Pessoas | Ruy Aguiar da Silva Leme. [S.I.]: c2008 Disponível em $<$ http://www.fea.usp.br/perfil.php?u=87\&tab=adm\&i=29>. Acesso em: 12/02/2013.

FACULDADE DE ECONOMIA, ADMINISTRAÇÃO E CONTABILIDADE DA UNIVERSIDADE DE SÃO PAULO. Pessoas | Antonio Delfim Netto. [S.I.]: c2008

Disponível em $<$ http://www.fea.usp.br/perfil.php?u=22\&tab=eae\&i=29>. Acesso em: 12/02/2013.

FAUSTO, B. História do Brasil. São Paulo: EDUSP, 1995.

FÁVERO, M. de L. de A. Anísio Teixeira e a Universidade do Distrito Federal, Revista Brasileira de História da Educação, v. 8, n. 2 [17], p. 161-180, 2008.

FONTANA, A.; FREY, J.H. The interview: from structured questions to negotiated text. In: DENZIN, N.K.; LINCOLN, Y.S. Handbook of qualitative research, Thousand Oaks: Sage, 2000. cap. 24, p. 645-672.

FOURNIER, V.; GREY, C. At the critical moment: conditions and prospects for critical management studies. Human Relations, v. 53, n. 1, p. 7-32, 2000.

FRENKEL, M.; SHENHAV, Y. From Americanization to Colonization: The Diffusion of Productivity Models Revisited. Organization Studies, v. 24, n. 9, p. 1537-1561, 2003.

GARRIDO, J. del A. As fontes orais na pesquisa histórica: uma contribuição ao debate. Revista Brasileira de História, v. 13, n. 25/26, p. 33-54, set. 1992 / ago. 1993.

GORDON, R.A.; HOWELL, J.E. Higher education for business. New York: Columbia University, 1959.

HIRST, M. Brasil-Estados Unidos: desencontros e afinidades. Rio de Janeiro: FGV, 2009. 
INEP. Censo Escolar. [S.I.]: c2011. Disponível em <http://portal.inep.gov.br/web/censoda-educacao-superior $>$. Acesso em: 12/05/2012.

JACQUES, R.S. History, historiography and organization studies: the challenge and the potential. Management \& Organizational History, v. 1, n. 1, p. 31-49, 2006.

KHURANA, R. From higher aims to hired hands: the social transformation of American business schools and the unfulfilled promise of management as a profession. Princeton: Princeton University Press, 2007.

KIPPING, M.; ENGWALL, L.; ÜSDIKEN, B. The transfer of management knowledge to peripheral countries. International Studies of Management and Organization, v. 38, n. 4, p. 3-16, 2008-9.

LEME, R.A. da S. Reestruturação Didática da Faculdade de Ciências Econômicas e Administrativas da U. S. P., Boletim no 15. São Paulo: FCEA, 1960. 55 p.

MARCH, J.G. Parochialism in the evolution of a research community: the case of Organization Studies. Management and Organization Review, v. 1, n. 1, p. 5-22, 2007.

MARCOVITCH, J. Pioneiros e empreendedores: a saga do desenvolvimento no Brasil. São Paulo: Saraiva, 2007.

MOTOYAMA, S. USP 70 Anos: Imagens de uma História Vivida. São Paulo: Universidade de São Paulo, 2006.

NOGUEIRA, O. IV. Os Institutos e as Fundações. 1. O Instituto de Administração - IA ( $1^{\mathrm{a}}$ fase). In: CANABRAVA, A.P. (Coord. e Org.); GUAGLIARDI, J.A. (Ed.). História da Faculdade de Economia e Administração da Universidade de São Paulo 1946/1981: v. 1. A Instituição. São Paulo: A Faculdade, 1984, p. 213-226.

NOGUEIRA, F.M.G. Ajuda externa para a educação brasileira: da USAID ao Banco Mundial. Cascavel: Edunioeste, 1999.

O CANGURU: Órgão do Centro Acadêmico "Visconde de Cairu”. São Paulo: Faculdade de Ciências Econômicas e Administrativas da Universidade de São Paulo, 1957.

PINHO, D. B. A FEA-USP no tempo: contribuição à memória de seus 60 anos. São Paulo: FEA/USP, 2006.

PINHO, D.B. II. A Consolidação: o Corpo Docente, os Departamentos e a Estrutura Curricular, 1946/69. 1. O Departamento de Ciências Econômicas. In: CANABRAVA, A.P. (Coord. e Org.); GUAGLIARDI, J.A. (Ed.). História da Faculdade de Economia e Administração da Universidade de São Paulo 1946/1981: v. 1. A Instituição. São Paulo: A Faculdade, 1984, p. 37-60.

SÃO PAULO (Estado). Decreto $n^{\circ} 36.361$, de 8 de março de 1960. Reorganiza o ensino na Faculdade de Ciências Econômicas e Administrativas da Universidade de São Paulo. Diário Oficial [do] Estado de São Paulo, São Paulo, SP, 8 mar. 1960. Disponível em: $<$ http://www.al.sp.gov.br/repositorio/legislacao/decreto/1960/decreto\%20n.36.361,\%20 de\%2008.03.1960.htm>. Acesso em: 05/02/2013. 
SRINIVAS, N. Mimicry and revival: the transfer and transformation of management knowledge to India, 1959-1990. International Studies of Management and Organization, v. 38, n. 4, p.38-57, 2008-9.

TAYLOR, D.A. Institution building in business administration: the Brazilian experience. East Lansing, Mich.: MSU International Business and Economic Studies, 1968.

TOLEDO, G.L. de; TREVISAN, G.D.M. II. A Consolidação: o Corpo Docente, os Departamentos e a Estrutura Curricular, 1946/69. 3. O Departamento de Administração. In: CANABRAVA, A.P.(Coord. e Org.); GUAGLIARDI, J.A. (Ed.). História da Faculdade de Economia e Administração da Universidade de São Paulo 1946/1981: v. 1. A Instituição. São Paulo: A Faculdade, 1984, p. 67-78.

ÜSDIKEN, B. Americanization of European management education in historical and comparative perspective: a symposium. Journal of Management Inquiry, v. 13, n. 2, p. 87-89, 2004.

ÜSDIKEN, B.; ÇETIN, B. From Betriebswirtschaftslehre to Human Relations: Turkish Management Literature before and after the Second World War. Business History, v. 43, n. 2, p. 99-124, 2001.

ÜSDIKEN, B.; WASTI, S. A. Preaching, teaching and researching at the periphery: academic management literature in Turkey, 1970-1999. Organization Studies, v. 30, n. 10, p. 1063-1082, 2009. 


\section{DADOS DOS AUTORES}

MIRIAM PIRES EUSTACHIO DE MEDEIROS VALE` vale.miriam@gmail.com Doutoranda em Administração de Empresas - Estudos Organizacionais pela FGV/ EAESP

Instituição de vinculação atual: Escola de Administração de Empresas de São Paulo Fundação Getúlio Vargas

São Paulo/SP - Brasil

Áreas de interesse em pesquisa: Institucionalismo, historiografia e neoinstitucionalismo.

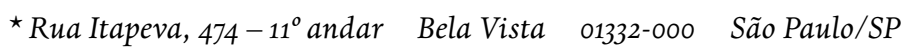

CARLOS OSMAR BERTERO carlos.bertero@fgv.br Doutor em Administração de Empreas pela Cornell University Instituição de vinculação: Escola de Administração de Empresas de São Paulo Fundação Getúlio Vargas

São Paulo/SP - Brasil

Áreas de interesse em pesquisa: História da educação em Administração no Brasil e Epistemologia ligada aos Estudos Organizacionais.

RAFAEL ALCADIPANI DA SILVEIRA rafael.alcadipani@fgv.br Pós-Doutor em Estudos Organizacionais pela University of Gothenburg Instituição de vinculação: Escola de Administração de Empresas de São Paulo Fundação Getúlio Vargas

São Paulo/SP - Brasil

Áreas de interesse em pesquisa: Etnografia e Perspectivas Pós-estruturalistas em Estudos Organizacionais. 